\title{
Neural correlates of spelling difficulties in Alzheimer`s disease
}

\author{
Javier Rodríguez-Ferreiro $^{\mathrm{a}}$, Carmen $_{\text {Martínez }}{ }^{\mathrm{b}}$, Ana-Julia Pérez-Carbajal $^{\mathrm{b}}$ \\ and Fernando Cuetos ${ }^{\mathrm{c}}$
}
${ }^{\text {a }}$ Departament de Psicologia Bàsica and IR3C, Universitat de Barcelona, Psg de la Vall d'Hebron 171. 08035, Barcelona, Spain
${ }^{\mathrm{b}}$ Hospital de Cabueñes, c/ Los Prados 395. 33203, Gijón, Spain.

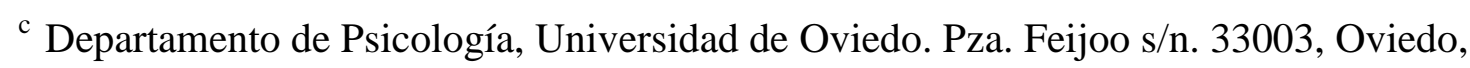 Spain

Corresponding author:

Javier Rodríguez-Ferreiro

Departament de Psicologia Bàsica

Universitat de Barcelona

Psg de la Vall d'Hebron 171

08035, Barcelona, Spain

eMail: rodriguezferreiro@ub.edu

Phone: 003493125157

Fax: 0034934021363 
Alzheimer's disease (AD) is associated with a general cognitive decline that affects the memory and language domains. Thus, an oral production deficit with a lexical-semantic origin has been widely observed in these patients. Their written production capacities, however, have been much less studied. We assessed the spelling abilities of $22 \mathrm{AD}$ patients and a group of matched healthy controls with a test battery including written picture naming and word and pseudoword dictation tests, as well as text dictation and spontaneous writing tasks. The results of the $\mathrm{AD}$ patients in the discriminative tasks were then entered into voxel-based morphometry analyses along with their grey matter volumes. The patient group presented a selective impairment for word dictation, which contrasted with a spared capacity to spell pseudowords, and showed more difficulties for words with arbitrary and rule-based orthography. Moreover, they also produced less complete syntactic units in the spontaneous writing task. These results point out the lexical-semantic, as opposed to sublexical, nature of the spelling deficit associated to AD. In addition, we recognized a mainly left-lateralized cortical network, including areas in the posterior inferior temporal lobe and the superior region of the parietal cortex, which might be responsible for this impairment. Other regions, such as the putamen, were also associated to the deficit. The results of this study, hence, improve our understanding of the neuropsychological and neuroanatomical mechanisms that underlie the cognitive symptoms associated to AD.

Keywords: Alzheimer's disease, spelling, writing, dysgraphia, voxel-based morphometry 


\section{Introduction}

The cognitive profile of Alzheimer's disease (AD) patients is mainly characterized by an episodic memory impairment that complicates the acquisition of new information (Fox, Warrington, Seiffer, Agnew, \& Rossor, 1998). However, a linguistic deficit is also present in many of the cases. The verbal output of $\mathrm{AD}$ patients, even in the early stages of the disease, lacks lexical diversity and presents semantic errors and circumlocutions (Cuetos, Rodríguez-Ferreiro, \& Menéndez, 2009; Cuetos, Rodríguez-Ferreiro, Sage, \& Ellis, 2012; González Nosti, Rodríguez Ferreiro, \& Cuetos Vega, 2008; RodríguezFerreiro, Davies, González-Nosti, Barbón, \& Cuetos, 2009). This linguistic pattern has been extensively documented in the oral domain, but there is much less evidence regarding writing abilities of these patients (for a review see Neils-Strunjas, GrovesWright, Mashima, \& Harnish, 2006).

Writing difficulties associated to the disease were observed by Alzheimer (1907) himself in the patient Auguste D.. Since then, a variety of deficits, with origins ranging from central to peripheral, have been described in the AD population. This line of research has gained certain popularity in the last years with the case-studies of the renowned writers Iris Murdoch (Garrard, Maloney, Hodges, \& Patterson, 2005; Pakhomov, Chacon, Wicklund, \& Gundel, 2011) and Agatha Christie (Lancashire, 2010).

The most common pattern of deficiency includes lexical dysgraphia (Croisile et al., 1996; Forbes, Shanks, \& Venneri, 2004; Hughes, Graham, Patterson, \& Hodges, 1997; Rapcsak, Arthur, Bliklen, \& Rubens, 1989) which may be concurrent with a phonological or sublexical deficit (Aarsland, Hoien, Larsen, \& Oftedal, 1996; Luzzatti, Laiacona, \& Agazzi, 2003; Neils \& Roeltgen, 1994; Pestell, Shanks, Warrington, \& Venneri, 2000; Platel et al., 1993) in later stages of the disease. In some cases, peripheral impairments are also present (Forbes et al., 2004; Horner, Heyman, Dawson, \& Rogers, 1988; Neils-Strunjas, Shuren, Roeltgen, \& Brown, 1998; Venneri, Pestell, \& Caffarra, 2002).

Following the influential model by Ellis (1982), lexical dysgraphia is characterized by errors in real word, as opposed to pseudoword, writing, and, more specifically, a diminished capacity to correctly spell irregular words with arbitrary orthography due to 
damage in the orthographic lexicon. On the other hand, phonological dysgraphia is present when the patient is incapable of writing pseudowords or rare unfamiliar words, and is caused by damage to the route that allows conversion of phonemes into their corresponding graphemes. Finally, peripheral dysgraphias involve a deficit in the mechanics of written output, including inappropriate allograph selection, inaccurate graphomotor patterns, awkward letter construction, poor letter spacing or spatial misalignment, among others.

Hence, the profile of spelling impairment present in $\mathrm{AD}$ patients is congruent with the deficit described in the oral domain and could be caused by degradation of specific linguistic subcomponents (Croisile et al., 1996; Forbes et al., 2004; Rapcsak et al., 1989). Nonetheless, some authors ascribe it to the general cognitive decline associated to dementia (Aarsland et al., 1996; Glosser \& Kaplan, 1989; Silveri, Corda, \& Di Nardo, 2007), especially in the cases of peripheral disorders (Neils-Strunjas et al., 1998).

The cognitive deficit associated to $\mathrm{AD}$ is grounded in the degradation of neural structures responsible of the different capacities affected. Histopathological studies have shown that neuronal changes associated to AD initiate in the hippocampus and the trans-enthorrinal region and, later on, spread to the neocortex (E. Braak et al., 1999; H. Braak \& Braak, 1995). More recently, automatic analyses of structural MRI scans through voxel-based morphometry (VBM) have confirmed that brain atrophy in AD patients starts in medial temporal structures and gradually extends to more lateral temporal regions as well as to the parieto-occipital area and the frontal lobe (Derflinger et al., 2011). In contrast, regions like the occipital pole, the sensoriomotor cortices and the cerebellum appear to be spared (Karas et al., 2003). In the last years, several studies have used VBM to examine the relationship between cortical changes and different symptoms of AD such as depression (Hyun Son, Hyun Han, Joon Min, \& Seok Kee, 2013), delusions (Bruen, McGeown, Shanks, \& Venneri, 2008) or semantic deficits (Rodríguez-Ferreiro et al., 2012). However, the link between the spelling impairment of AD patients and their pattern of brain atrophy remains unstudied.

Historically, peripheral writing mechanisms have been situated in the Exner's area, just above Broca's area in the left frontal lobe (Exner, 1881), while central components have 
been associated to the angular gyrus in the parietal lobe (Dejerine, 1891). Thus, the orthographic representations (Patterson \& Kay, 1982; Rapcsak, Rubens, \& Laguna, 1990) and lesions in the posterior temporal area appear to be linked to lexical agraphia (Croisile, Trillet, Laurent, Latombe, \& Schott, 1989) as well as to tasks involving the retrieval of orthographic word forms (Beeson et al., 2003). Moreover, activity in the angular gyrus has been specifically associated with lexical subprocesses of writing in AD participants (Penniello et al., 1995).

In this study we aimed to obtain a broad profile of the spelling capacities of our participants and investigate its relation with brain atrophy. Given its preeminence in the $\mathrm{AD}$ population, we decided to focus in the more common deterioration of central, rather than peripheral, components of written language processing. Thus, we measured the amount of correctly spelled words in each subtest while ignoring errors related to peripheral subcomponents of written language, such as case misuse or misalignment. We assessed the capacity of a group of AD patients to write in different tasks, including spontaneous narrative, dictation and written naming, with both sentence and single word stimuli. In order to differentiate between lexical and sublexical contributions to spelling, we also included a pseudoword dictation task, and we distinguished between different types of real word stimuli depending on their degree of spelling ambiguity in the word writing task. Due to the high amount of one-to-one correspondences between sounds and letters in the Spanish orthographic system, most of the words can be spelled correctly following the basic, sublexical, phoneme-to-grapheme correspondences. On the other hand, the correct spelling of words containing non-univocal correspondences (i.e. /b/ to "b" or "v"; /y/ to "y" or "ll") depends entirely on lexical knowledge, although orthographic rules based on letter groupings might be applied to assist accurate spelling in some cases (i.e. all words ending in /-iyo/ are spelled with "ll", and not "y"; all words starting with /ue/ are spelled with an initial mute "h").

The results of the $\mathrm{AD}$ patients in those tasks sensitive enough to differentiate between healthy and impaired seniors were then introduced into VBM analyses along with their brain volumes in order to investigate the relationship between cognitive capacity and the degradation of neural structures. 


\section{Materials and methods}

\subsection{Participants}

Twenty-two outpatients with probable AD and the same number of healthy seniors took part in the study. They all were native Spanish speakers and came from similar socioeconomic backgrounds. None of them had a history of alcohol abuse, or neurological or psychiatric disorders other than $\mathrm{AD}$. Other possible sources of cognitive impairment such as focal lesions or microbleeds were ruled out by neuroimaging tests. Participants with sensory impairments were also ruled out from the sample. All the patients had been diagnosed a priori by the neurology group of the Cabueñes Hospital (Gijón, Spain) according to the NINCDS-ADRDA criteria (McKhann et al., 1984; Tierney et al., 1988). The severity of dementia was assessed according to the Global Deterioration Scale (GDS, Reisberg, Ferris, de Leon, \& Crook, 1982). Eighteen of the patients were in stage four, three were in stage five and only one was in stage six. A group of 22 healthy seniors selected amongst the participants' relatives participated in the experiment as a control group. The two groups of participants were matched on age and years of education. Nevertheless, differences in cognitive capacity between the AD and control group were evidenced by their scores in the MiniMental State Evaluation test (MMSE, Folstein, Folstein, \& McHugh, 1975). A summary of the demographic characteristics of the participants is presented in Table 1. Informed consent was obtained from all participants or their caregivers where appropriate. Ethical approval was obtained from the hospital board where data collection was undertaken.

\begin{tabular}{lcccc} 
& & Age & $\begin{array}{c}\text { Years of } \\
\text { Schooling }\end{array}$ & $\begin{array}{c}\text { MMSE } \\
\text { out of. 30 }\end{array}$ \\
\cline { 2 - 5 } & $\mathrm{n}($ females $)$ & $\mathrm{M}(\mathrm{SD})$ & $\mathrm{M}(\mathrm{SD})$ & $\mathrm{M}(\mathrm{SD})$ \\
\hline $\mathrm{AD}$ & $22(12)$ & $75.4(4.3)$ & $8.6(2.9)$ & $20.1(3.8)$ \\
Control & $22(12)$ & $75.4(4)$ & $8(2.7)$ & $29.3(0.7)$ \\
\hline
\end{tabular}

Table 1. Summary of participants' characteristics

\subsection{Tasks}

We present the results obtained by the participants in six tasks that were administered in the context of a wider assessment protocol. Five of the tasks were designed to study the participants' writing abilities: written picture naming; text writing to dictation; word writing to dictation, pseudoword writing to dictation; and narrative writing. In order to 
confirm the presence of the lexical-semantic deficit reported in previous studies an oral picture naming task was also included in the battery as a control test for the oral production domain. The different tasks were distributed in two sessions separated seven days apart. Longer tasks were split into two and each half was presented in one of the sessions. For those tasks with overlapping stimuli sets, we avoided repetition of stimuli in the same session.

\subsubsection{Oral picture naming}

A list of 50 pictures were selected from the coloured version (Rossion \& Pourtois, 2004) of the Snodgrass and Vanderwart (1980) picture set. They all had high name agreement values (>85\%) and corresponded to familiar objects $(\mathrm{M}=5.77, \mathrm{SD}=0.77)$. Picture names ranged from three to ten phonemes $(\mathrm{M}=5.76, \mathrm{SD}=1.44)$ and their lexical frequency values (LEXESP, Sebastián-Gallés, Carreiras, Cuetos, \& Martí, 2000) were between 0.36 and $107.86(\mathrm{M}=13.15, \mathrm{SD}=18.65)$.

\subsubsection{Written picture naming}

The participant was presented with 15 object pictures, natural kinds (i.e. "oveja" sheep; "cebolla" onion...) and six artefacts ("campana" bell; "cepillo" brush...), from the list used in the oral naming task. The average length of the picture names was 6.4 letters $(\mathrm{SD}=1.8$, range 4-11). Their frequency values were between 0.89 and $34.46(\mathrm{M}=8.6$, $\mathrm{SD}=9.25)$. Each picture was presented in print in a separate paper sheet. The participant was asked to write down the name of the object. No time limit was imposed so the trial ended when the patient had finished writing or when she said "I don't know". No semantic or phonological cues were given at any time. The participant was free to write the answers in lower or upper case and to list the picture names in rows or columns. The amount of correct responses was registered.

\subsubsection{Text writing to dictation}

A short text piece was constructed for this investigation. It consisted of two sentences including a total of 23 words: ten function words, seven nouns, five verbs and one adjective ("Después de salir del colegio Juan fue al parque de Gijón. Se encontró con Pedro y, juntos, vieron palomas que volaban hacia Oviedo" - After leaving school Juan went to Gijon's park. He met Pedro and, together, they saw pigeons flying to Oviedo). The experimenter read the text to the participant, who was asked to write it down. In 
order to minimize possible difficulties related to a memory deficit, the experimenter would repeat the text several times until the participant had finished writing it. Again, the participant was free to use upper or lower case lettering. We registered the amount of correctly written words.

\subsubsection{Word writing to dictation}

A list of 60 object-nouns between four and eight letters-long $(\mathrm{M}=5.7, \mathrm{SD}=1.1)$ was read aloud by the experimenter for the participant to transcribe. The average lexical frequency of the words (Sebastián-Gallés et al., 2000) was $10.4(\mathrm{SD}=10.6)$. The list comprised 20 natural kinds (i.e. "pavo" - turkey; "fresa" - strawberry;...) and 40 artefacts (i.e. "casco" - helmet; "tornillo" - screw;...). The words also differed in their orthographic characteristics. Thus, the subgroup of regular orthography included 20 words that can be spelled unambiguously following univocal phoneme-to-grapheme correspondences (i.e. "falda" - skirt; "arco" - bow; .. frequency $\mathrm{M}=10.7, \mathrm{SD}=9.2$ ). The rule-based subgroup comprised 20 orthographically ambiguous words that can be spelled correctly relying on orthographic rules based on letter groupings (i.e. "anillo" ring, but not "aniyo"; "hueso" - bone, but not "ueso";... frequency M=9.8, SD=10.6). Finally, the group of arbitrary orthography consisted of 20 orthographically ambiguous words for which there are no orthographic rules. These words, thus, can only be spelled correctly relying on lexical knowledge (i.e. "banco" - bench, but not "vanco"; "hada" fairy, but not "ada"; .. frequency $\mathrm{M}=10.3, \mathrm{SD}=11.7)$. No cues were given by the experimenter even when the participant asked for help. In those cases she was encouraged to write the word down even if she was not sure of the orthography. We measured the amount of correct responses.

\subsubsection{Pseudoword writing to dictation}

Twenty legal pseudowords ranging from four to seven letters $(\mathrm{M}=5.35, \mathrm{SD}=0.93)$ were constructed to be used in this task (i.e. "tugo"; "tronfa"...). The procedure was the same used in the word writing task.

\subsubsection{Narrative writing}

The participant was asked to write a story based on three cartoons depicting a man that was preparing to go fishing. The cartoons were presented in print and contained black and white lineal drawings. No length or time restrictions were given to the participant. 
We registered the total number of correctly written words written by the participant as measure of word re-usage. We also measured the number of T units (Moran, 1981) or minimum complete syntactic units.

\subsection{MRI acquisition and analysis}

All the participants underwent MRI with a 1.5T Signa EchoSpeed scanner (GE medical systems) in the Cabueñes Hospital. The time elapsed between the furthest behavioural testing and the MRI scan was always less than two months, with 15 of the cases being scanned within ten days of the testing session. A heavily T1-weighted structural 3D sequence was used to obtain high resolution images (SPGR; TR 15ms, TE 6ms, flip angle $15^{\circ}, 3$ NEX) with 120 sagittal sections. Matrix size was 256 × 256 × 232 with a $280 \mathrm{~mm}$ field of view. Voxel dimensions were $1.09 \mathrm{~mm} \times 1.09 \mathrm{~mm} \times 0.80 \mathrm{~mm}$. The image preprocessing steps and statistical analyses were conducted with the Statistical Parametric Mapping software package version 8 (The Wellcome Trust Centre for Neuroimaging, London). Segments of grey and white matter, as well as cerebrospinal fluid, were obtained using unified tissue-segmentation (Ashburner \& Friston, 2005). Then, Diffeomorphic Anatomic Registration through Exponentiated Lie (DARTEL, Ashburner, 2007) algebra normalisation procedures were applied. Finally, normalised grey matter volume images were smoothed using a $10 \mathrm{~mm}$ Full Width at Half Maximum (FWHM) Gaussian kernel in order to reduce the variability between participants.

\section{Results}

The behavioural results of the $\mathrm{AD}$ and control groups are summarized in Table 2. Scores obtained by the two groups in all the tasks and subtests were compared by means of nonparametric Mann-Whitney tests due to violations of the normality assumption (Shapiro-Wilk $\mathrm{p}<.05$ ). We used a Bonferroni correction to adjust for multiple comparisons, so all effects are interpreted at a .005 level of significance.

\begin{tabular}{llll} 
& & $\begin{array}{l}\text { AD } \\
\text { mean(SD) }\end{array}$ & $\begin{array}{l}\text { Control } \\
\text { mean(SD) }\end{array}$ \\
\hline Tasks & max. & & \\
\hline Oral Naming & 50 & $35.9(12.4)$ & $47.8(2.7)^{*}$ \\
Written Naming & 15 & $8.5(3.9)$ & $12.5(1.7)^{*}$
\end{tabular}




\begin{tabular}{llll} 
Words dictation & 60 & $43.1(12.5)$ & $53.8(4.6)^{*}$ \\
regular & 20 & $17(3.79)$ & $18.9(1.3)$ \\
rule-based & 20 & $14.1(4.8)$ & $18.3(1.4)^{*}$ \\
arbitrary & 20 & $12(4.8)$ & $16.6(3)^{*}$ \\
Pseudowords dictation & 20 & $16.5(4.1)$ & $19(0.9)$ \\
Text dictation & 23 & $19(5.2)$ & $21.5(1.3)$ \\
Narrative Text & & & \\
T Units & - & $2(1.5)$ & $3.8(1.8)^{*}$ \\
Type/Token ratio & - & $0.8(0.2)$ & $0.8(0.1)$ \\
\hline p $<.005$ in the comparison between $\mathrm{AD}$ and control
\end{tabular}

Table 2. Summary of behavioural results

Significant differences appeared in six of the measures, including the oral $(U=46, z=-$ 4.635, $\mathrm{p}<.001)$ and written $(\mathrm{U}=83, \mathrm{z}=-3.762, \mathrm{p}<.001)$ naming tasks as well as the word dictation task $(\mathrm{U}=75, \mathrm{z}=-3.927 \mathrm{p}<.001)$. No significant differences appeared in the pseudoword $(\mathrm{U}=142, \mathrm{z}=-2.418, \mathrm{p}=.016)$ or text $(\mathrm{U}=210.5 \mathrm{z}=-1.227, \mathrm{p}=.22)$ dictation tests. Regarding the narrative writing task, significant differences were observed in the amount of $\mathrm{T}$ units produced $(\mathrm{U}=112 \mathrm{z}=-3.122, \mathrm{p}=.002)$ but not in the type/token ratios $(\mathrm{U}=233.5, \mathrm{z}=-0.2, \mathrm{p}<.842)$. Finally, the analyses of the three word dictation subcategories showed significant differences between the two participant groups in the lists of rule-based $(\mathrm{U}=88 \mathrm{z}=-3.649, \mathrm{p}<.001)$ and arbitrary orthography $(\mathrm{U}=95 \mathrm{z}=-3.469$, $\mathrm{p}=.001)$ but not for words with regular orthography $(\mathrm{U}=159.5 \mathrm{z}=-1.996, \mathrm{p}=.046)$.

Separate regression analyses were conducted with the smoothed modulated normalised grey matter segments of each participant in the AD group and their accuracy scores in each of the spelling tasks that evidenced differences with the scores obtained by the control group. Height threshold was set at $\mathrm{p}<.001$ (uncorrected) for all analyses. In order to reduce the problems associated to multiple comparisons, we applied an objective average-based mask created by means of the SPM Masking toolbox. This method is specifically recommended for the study of atrophied brains (Ridgway et al., 2009).

The analyses included the patients' ages, years of education and total intracranial volume values as covariates. Only significant clusters comprising a minimum of 5 consecutive voxels were taken into consideration. Table 3 summarizes the areas in the 
cerebral cortex where grey matter volume values significantly correlated with the patients' scores. Anatomical regions were identified using the Talairach Daemon Client (http://www.talairach.org/), following conversion of the Montreal Neurological Institute coordinates extracted from the SPM analyses into Talairach coordinates using the GingerAle application (http://www.brainmap.org/ale/).

\begin{tabular}{|c|c|c|c|c|c|}
\hline \multirow{2}{*}{$\begin{array}{c}\text { Voxels } \\
\text { in cluster }\end{array}$} & \multirow{2}{*}{$\begin{array}{l}\mathrm{Z} \text { value at } \\
\text { local } \\
\text { maximum }\end{array}$} & \multicolumn{3}{|c|}{ Talairach Coordinates } & \multirow[t]{2}{*}{$\begin{array}{c}\text { Brain region } \\
\text { (Brodmann's area) }\end{array}$} \\
\hline & & $\mathrm{x}$ & $\mathrm{y}$ & $\mathrm{z}$ & \\
\hline \multicolumn{6}{|l|}{ Written Naming } \\
\hline 291 & 4.38 & 19 & 62 & 15 & Right Superior Frontal (10) \\
\hline 184 & 4.13 & -45 & -58 & 8 & Left Middle Temporal (39) \\
\hline 234 & 3.68 & -23 & 4 & 7 & Left Putamen \\
\hline 34 & 3.57 & -11 & -95 & -18 & Left Lingual (17) \\
\hline 22 & 3.52 & -22 & -87 & -12 & Left Fusiform (18) \\
\hline 51 & 3.36 & 19 & -67 & 46 & Right Precuneus (7) \\
\hline 15 & 3.35 & -36 & -74 & -2 & Left Inferior Occipital (19) \\
\hline 40 & 3.27 & -24 & -86 & 12 & Left Middle Occipital (19) \\
\hline 21 & 3.24 & -48 & -18 & 34 & Left Postcentral (3) \\
\hline 5 & 3.19 & -45 & -67 & 19 & Left Middle Temporal (39) \\
\hline \multicolumn{6}{|c|}{ Words to Dictation } \\
\hline 69 & 3.34 & 16 & 59 & 17 & Right Superior Frontal (10) \\
\hline \multicolumn{6}{|c|}{ Narrative Text (T Units) } \\
\hline 403 & 4.68 & -45 & -56 & 9 & Left Middle Temporal (39) \\
\hline 274 & 3.97 & -20 & -4 & 4 & Left Globus Palidus \\
\hline 77 & 3.37 & -47 & 21 & -19 & Left Superior Temporal (38) \\
\hline 5 & 3.12 & -42 & 8 & -28 & Left Superior Temporal (38) \\
\hline
\end{tabular}


Table 3. Results of the correlation analyses

\section{Discussion}

In this study we aimed to assess the writing abilities of a group of AD patients by means of a test battery that included a selection of tasks designed to establish a wide profile of their spelling capacity. Moreover, we intended to determine the relationship between writing dysfunction and grey matter loss in different brain areas by entering the participants' behavioural results into multiple voxel-based regression analyses with cortical volume values extracted from high resolution three-dimensional brain MRI scans.

Our results confirmed the presence of a language deficiency in AD patients with similar characteristics to that observed in previous studies. Hence, significant differences between the experimental and control groups were observed in all the tasks except for the pseudoword and text dictation tests. The oral language impairment of $\mathrm{AD}$ patients reported in previous studies (Cuetos et al., 2012; González Nosti et al., 2008; Rodríguez-Ferreiro et al., 2009) was also present in our participants, according to their impaired results in the control oral naming task. Furthermore, this deficit appeared to extend also into the written language domain, as evidenced by significantly poorer scores obtained by the $\mathrm{AD}$ group in the written naming test.

A prominence of lexical-semantic, as opposed to sublexical, deficit was pointed out by the selective impairment for word dictation, which contrasted with a spared capacity to spell pseudowords. The lexical-semantic nature of the disorder was also evidenced by the comparison of the results obtained in the three word dictation subtests including words with different orthographic characteristics. Differences between the two groups of participants appeared in the rule-based and arbitrary orthography lists. The stronger dependence of these kinds of words on lexical information, compared to words with regular orthography, indicates the lexical origin of the impairment. Specific difficulties to retrieve orthographic lexical representations have been previously reported in studies with $\mathrm{AD}$ patients and could be ascribed to the deterioration of language-specific processes (Croisile et al., 1996; Forbes et al., 2004; Hughes et al., 1997; Rapcsak et al., 1989). 
On the other hand, proof of a spelling deficit at the text level was observed in the appeared between the type/token ratios of the two groups, what indicates that $\mathrm{AD}$ patients are not inclined to re-use words more frequently than healthy participants, we observed significant differences in the amount of T Units they produced. An impaired capacity for narrative writing, evidenced by the production of fewer and less complex sentences, has already been observed in AD patients (Glosser, Kohn, Sands, Grugan, \& Friedman, 1999; Kemper, Greiner, Marquis, Prenovost, \& Mitzner, 2001). This effect is, again, consistent with the lexical-semantic nature of the disorder, which prevents $\mathrm{AD}$ patients from producing as many sound sentences as healthy seniors.

Furthermore, our results show an association between the cognitive dysfunction that affects written language production in $\mathrm{AD}$ patients and reduced brain volumes in different areas distributed throughout the neocortex, including mainly left-lateralized regions in the temporal lobe (see Figure 1).

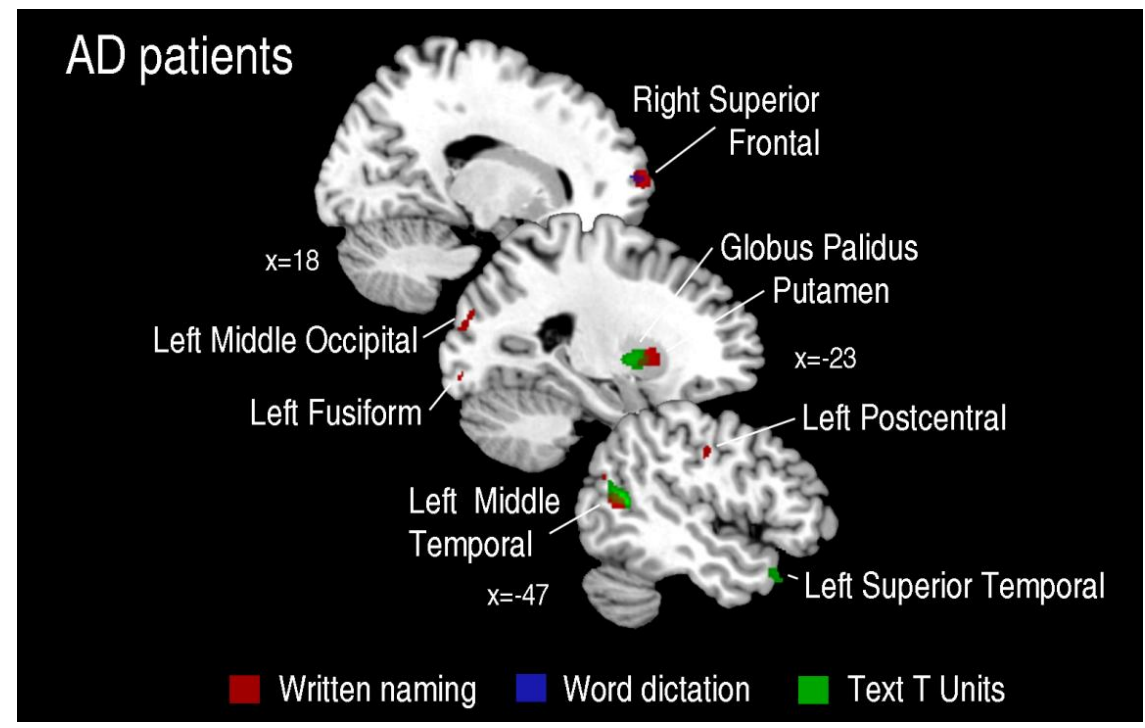

Figure 1. Regions significantly correlated with grey matter density in the written picture naming test

Previous studies have pointed out a link between the temporo-parietal cortex and the processing of lexical orthographic forms (Beeson et al., 2003; Patterson \& Kay, 1982; Rapcsak et al., 1990) as well as agraphic disorders (Croisile et al., 1989). Our results show a significant association between poor spelling and volume loss in the superior region of the parietal lobe (BA 7). Activity in this area has been related to generative 
single word and alphabet writing tasks (Beeson et al., 2003), and is argued to support also point out a significant correlation between poor written naming and cortical atrophy in the left postcentral gyrus, a region that has been suggested to participate in the representation of letter shape and identity in writing tasks (Dufor \& Rapp, 2013)

The posterior inferior region of the left temporal cortex has also been associated with central components of spelling (Purcell, Turkeltaub, Guineverem, \& Rapp, 2011). Our results confirm this association, as we have observed a significant correlation between poor written naming and decreased volume in the left fusiform gyrus. However, our results also show an association between poor spelling and cortical atrophy in posterior middle and anterior superior areas of the left temporal lobe.

Significant associations between poor spelling capacities and grey matter loss in medial structures like the putamen and the globus palidus were also observed in our results. The basal ganglia are known to be affected by atrophy caused by AD (Tang, Holland, Dale, Younes, \& Miller, 2014). Moreover, the putamen has been shown to be active during generative writing (Beeson et al., 2003) and is consistently associated to the central processes of spelling (Purcell et al., 2011).

On the other hand, we did not find evidence of a link between writing difficulties and brain atrophy in the angular gyrus. This region has long been suggested to control semantically guided retrieval of orthographic word forms for writing (Dejerine, 1891; Penniello et al., 1995). Nevertheless, the absence of significant associations between spelling tasks and activity in this area in more recent studies (Beeson et al., 2003; Purcell et al., 2011) casts doubt on this relationship.

In conclusion, our study confirmed the presence of a deficit for written language production in AD patients, which appears to have its origin in a lexical-semantic impairment. In addition, we recognized a cortical network, including areas in the superior region of the parietal cortex and the inferior temporal area, which might be responsible for this deficit. Medial structures, such as the putamen, were also associated to the disorder. Further studies with a wider sample and more specific tasks might 
determine whether these areas are critically involved in the spelling impairment present in $\mathrm{AD}$ patients.

\section{Acknowledgements}

This study was supported by grant PSI2012-31913 from the Spanish Government. 


\section{References}

Aarsland, D., Hoien, T., Larsen, J. P., \& Oftedal, M. (1996). Lexical and non-lexical spelling deficits in dementia of the Alzheimer's type. Brain and Language, 52, $551-563$.

Alzheimer, A. (1907). Uber eine eigenartige Erkrankung der Hirinde. Allgemeine Zeitschrift für Psychiatrie und psychisch-Gerichtliche Medizin, 64, 146-148.

Ashburner, J. (2007). A fast diffeomorphic image registration algorithm. Neuroimage, $38,95-113$.

Ashburner, J., \& Friston, K. J. (2005). Unified segmentation. Neuroimage, 26, 839-851.

Beeson, M. P., Rapcsak, S. Z., Plante, E., Chargualf, J., Chung, A., Johnson, S., \& Trourard, T. (2003). The neural substrates of writing: A functional magnetic resonance imaging study. Aphasiology, 17, 647-665.

Braak, E., Griffing, K., Arai, K., Bohl, J., Bratzke, H., \& Braak, H. (1999). Neuropathology of Alzheimer's disease: what is new since A. Alzheimer? European Archives of Psychiatry and Clinical Neuroscience, 249, 14-22.

Braak, H., \& Braak, E. (1995). Staging of Alzheimer's disease-related neurofibrillary changes. Neurobiology of Aging, 16, 271-284.

Bruen, P. D., McGeown, W. J., Shanks, M. F., \& Venneri, A. (2008). Neuroanatomical correlates of neuropsychiatric symptoms in Alzheimer's disease. Brain, 131, 24552463.

Croisile, B., Brabant, M. J., Carmoi, T., Lepage, Y., Aimard, G., \& Trillet, M. (1996). Comparison between oral and written spelling in Alzheimer's disease. Brain and Language, 54, 361-387.

Croisile, B., Trillet, M., Laurent, B., Latombe, B., \& Schott, B. (1989). Agraphie lexicale par hematome temporo-parietal gauche. Revue Neurologique, 145, 287292.

Cuetos, F., Rodríguez-Ferreiro, J., \& Menéndez, M. (2009). Semantic markers in the diagnosis of neurodegenerative dementias. Dementia and geriatric cognitive disorders, 28(3), 267-274. doi:10.1159/000242438

Cuetos, F., Rodríguez-Ferreiro, J., Sage, K., \& Ellis, A. W. (2012). A fresh look at the predictors of naming accuracy and errors in Alzheimer's disease. Journal of neuropsychology, 6(2), 242-56. doi:10.1111/j.1748-6653.2011.02025.x

Dejerine, J. (1891). Sur un cas de cécité verbale avec agraphie, suivi d'autopsie. Mémoires Société Biologique, 3, 197-201. 
Derflinger, S., Sorg, C., Gaser, C., Myers, N., Arsic, M., Kurz, A., ... Mühlau, M. (2011). Grey-Matter Atrophy in Alzheimer's Disease is Asymmetric but not Lateralized. Journal of Alzheimer's Disease, 25, 347-357.

Dufor, O., \& Rapp, B. (2013). Letter representations in writing: an fMRI adaptation approach. Frontiers in Psychology. doi:10.3389/fpsyg.2013.00781

Ellis, A. (1982). Spelling and writing (and reading and speaking). In A. Ellis (Ed.), Normality and pathology in cognitive functions (pp. 113-146). London: Academic Press.

Exner, S. (1881). Untersuchungen über die Lokalisation der Functionen in der Grosshirnrinde des Menschen. Viena: Wilhelm Braunmüller.

Folstein, M. F., Folstein, S. E., \& McHugh, P. R. (1975). Mini-Mental State: A practical method fro grading the cognitive state of patients for the clinician. Journal of Psychiatric Research, 12, 189-198.

Forbes, K. E., Shanks, M. F., \& Venneri, A. (2004). The evolution of dysgraphia in Alzheimer's disease. Brain Research Bulletin, 63, 19-24.

Fox, N. C., Warrington, E. K., Seiffer, A. L., Agnew, S. K., \& Rossor, M. N. (1998). Presymptomatic cognitive deficits in individuals at risk of familial Alzheimer's disease. A longitudinal prospective study. Brain, 12, 1631-1639.

Garrard, P., Maloney, L. M., Hodges, J. R., \& Patterson, K. (2005). The effects of very early Alzheimer's disease on the characteristics of writing by a renowned author. Brain, 128, 250-260.

Glosser, G., \& Kaplan, E. (1989). Linguistic and nonlinguistic impairments in writing: A comparison of patients with focal and multifocal CNS disorders. Brain and Language, 37, 357-380.

Glosser, G., Kohn, S. E., Sands, L., Grugan, P. K., \& Friedman, R. B. (1999). Impaired spelling in Alzheimer's disease: A linguistic deficit? Neuropsychologia3, (807815).

González Nosti, M., Rodríguez Ferreiro, J., \& Cuetos Vega, F. (2008). Variability in the semantic errors produced by brain-injured patients. Psicothema, 20(4), 795-800.

Horner, J., Heyman, A., Dawson, D., \& Rogers, H. (1988). The relationship of agraphia to the severity of dementia in Alzheimer's disease. Archives of Neurology, 45, $760-763$.

Hughes, J. C., Graham, N., Patterson, K., \& Hodges, J. R. (1997). Dysgraphia in mild dementia of Alzheimer's type. Neuropsychologia, 35, 533-545.

Hyun Son, J., Hyun Han, D., Joon Min, K., \& Seok Kee, B. (2013). Correlation between gray matter volume in the temporal lobe and depressive symptoms in patients with Alzheimer's disease. Neuroscience Letters, 548, 15-20. 
Karas, G. B., Burton, E. J., Rombouts, S. A. R. B., van Schijndel, R. A., O’Brien, J. T., Scheltens, P., ... Barkhof, F. (2003). A comprehensive study of gray matter loss in patients with Alzheimer's disease using optimized voxel-based morphometry. NeuroImage, 18, 895-907.

Kemper, S., Greiner, L. H., Marquis, J. G., Prenovost, K., \& Mitzner, T. L. (2001). Language decline across the life span: Findings from the Nun Study. Psychology and Aging, 16, 227-239.

Lancashire, I. (2010). Forgetful muses: Reading the author in the text. Toronto: University of Toronto Press, Scholarly Publishing Division.

Luzzatti, A., Laiacona, M., \& Agazzi, D. (2003). Multiple patterns of writing disorders in dementia of the Alzheimer type and their evolution. Neuropsychologia, 41, 759772 .

McKhann, G., Drachman, D., Folstein, M., Katzman, R., Price, D., \& Stadlan, E. M. (1984). Clinical diagnosis of Alzheimer's disease: report of the NINCDS-ADRDA work group under the auspices of the Department of Health and Human Services Task Force on Alzheimer's disease. Neurology, 34, 939-944.

Moran, M. (1981). Performance of learning-disabled and low achieving secondary student on formal features of a paragraph-writing task. Learning Disability Quarterly, 4, 271-280.

Neils, J., \& Roeltgen, D. (1994). Does lexical dysgraphia occur in early Alzheimer's disease? Journal of Medical Speech-Language Pathology, 2, 281-289.

Neils-Strunjas, J., Groves-Wright, K., Mashima, P., \& Harnish, S. (2006). Dysgraphia in Alzheimer's Disease: A review for clinical and research purposes. Journal of Speech, Language, and Hearing Research, 49, 1313-1330.

Neils-Strunjas, J., Shuren, J., Roeltgen, D., \& Brown, C. (1998). Perseverative writing errors in a patient with Alzheimer's disease. Brain and Language, 63, 303-320.

Pakhomov, S., Chacon, D., Wicklund, M., \& Gundel, J. (2011). Computerized assessment of syntactic complexity in Alzheimer's disease: a case study of Iris Murdoch's writing. Behavior Research Methods, 43, 136-144.

Patterson, K. E., \& Kay, J. (1982). Letter-by-letter reading: Psychological descriptions of a neurological syndrome. Quarterly Journal of Experimental Psychology, 34A, 411-441.

Penniello, M. J., Lambert, J., Eustache, F., Petit-Taboué, M. C., Barré, L., Viader, F., ... Baron, J. C. (1995). A PET study of the functional neuroanatomy of writing impairment in Alzheimer's disease The role of the left supramarginal and left angular gyri. Brain, 118(3), 697-706. 
Pestell, S., Shanks, M. F., Warrington, J., \& Venneri, A. (2000). Quality of spelling breakdown in Alzheimer's disease is independent of disease progression. Journal of Clinical and Experimental Neuropsychology, 22, 599-612.

Platel, H., Lambert, J., Eustache, F., Cadet, B., Dary, M., Viader, F., \& Lechevalier, B. (1993). Characteristics and evolution of writing impairment in Alzheimer's disease. Neuropsychologia, 31, 1147-1158.

Purcell, J. J., Turkeltaub, P. E., Guineverem, F. E., \& Rapp, B. (2011). Examining the central and peripheral processes of written word production through meta-analysis. Frontiers in Psychology2. doi:10.3389/fpsyg.2011.00239

Rapcsak, S. Z., Arthur, S. A., Bliklen, D. A., \& Rubens, A. B. (1989). Lexical agraphia in Alzheimer's disease. Archives of Neurology, 46, 65-68.

Rapcsak, S. Z., Rubens, A. B., \& Laguna, J. F. (1990). From letters to words: Procedures for word recognition in letter-by-letter reading. Brain and Language, $38,504-514$.

Reisberg, B., Ferris, S., de Leon, M., \& Crook, T. (1982). The global deterioration Scale of Assessment of primary degenerative dementia. American Journal of Psichiatry, $139,1136-1139$.

Ridgway, G. R., Omar, R., Ourselin, S., Hill, D. L. G., Warren, J. D., \& Fox, N. C. (2009). Issues with threshold masking in voxel-based morphometry of atrophied brains. NeuroImage, 44(1), 99-111. doi:10.1016/j.neuroimage.2008.08.045

Rodríguez-Ferreiro, J., Cuetos, F., Monsalve, A., Martínez, C., Pérez, A. J., \& Venneri, A. (2012). Establishing the relationship between cortical atrophy and semantic deficits in Alzheimer's disease and Mild Cognitive Impairment patients through Voxel-Based Morphometry. Journal of Neurolinguistics, 25, 139-149.

Rodríguez-Ferreiro, J., Davies, R. A. I., González-Nosti, M., Barbón, A., \& Cuetos, F. (2009). Name agreement, frequency and age of acquisition, but not grammatical class, affect object and action naming in Spanish speaking participants with Alzheimer's disease. Journal of Neurolinguistics, 22(1), 37-54.

Rossion, B., \& Pourtois, G. (2004). Revisiting Snodgrass and Vanderwart's object pictorial set: The role of surface detail in basic-level object recognition. Perception, 33, 217-236.

Sebastián-Gallés, N., Carreiras, M., Cuetos, F., \& Martí, M. A. (2000). LEXESP. Léxico informatizado del español. Barcelona: Publicacions UB.

Seitz, R. J., Canavan, A. G. M., Yágüez, L., Herzog, H., Tellmann, L., Knorr, U., ... Hömberg, V. (1997). European Juumal of Neuroscience, Vol. 9, pp. 378-389, 1997 0 European Neuroscience Association Representations of Graphomotor Trajectories in the Human Parietal Cortex: Evidence for Controlled Processing and Automatic Performance. European Juumal of Neuroscience, 9, 378-389. 
Silveri, M. C., Corda, F., \& Di Nardo, M. (2007). Central and peripheral aspects of writing disorders in Alzheimer's disease. Journal of Clinical and Experimental Neuropsychology, 29, 179-186.

Snodgrass, J. G., \& Vanderwart, M. (1980). A standarized set of 260 pictures: Norms for name agreement, image agreement, familiarity and visual complexity. Journal of Experimental Psychology: Human Learning and Memory, 6, 174-215.

Tang, X., Holland, D., Dale, A. M., Younes, L., \& Miller, M. I. (2014). Shape abnormalities of subcortical and ventricular structures in mild cognitive impairment and Alzheimer's disease: Detecting, quantifying, and predicting. Human Brain Mapping, in press.

Tierney, M. C., Fisher, R. H., Lewis, A. J., Zorzitto, M. L., Snow, W. G., \& Reid, D. W. (1988). The NINCDS-ADRDA work group criteria for the clinical diagnosis of probable Alzheimer's disease: A clinico-pathologic study of 57 cases. Neurology, $38,359-364$.

Venneri, A., Pestell, S., \& Caffarra, P. (2002). Independent representations for cursive and print style: Evidence from dysgraphia in Alzheimer's disease. Cognitive Neuropsychology, 19, 387-400. 
Table 1. Summary of participants' characteristics

\begin{tabular}{lcccc} 
& & Age & $\begin{array}{c}\text { Years of } \\
\text { Schooling }\end{array}$ & $\begin{array}{c}\text { MMSE } \\
\text { out of. 30 }\end{array}$ \\
\cline { 2 - 5 } & $\mathrm{n}($ females $)$ & $\mathrm{M}(\mathrm{SD})$ & $\mathrm{M}(\mathrm{SD})$ & $\mathrm{M}(\mathrm{SD})$ \\
\hline AD & $22(12)$ & $75.4(4.3)$ & $8.6(2.9)$ & $20.1(3.8)$ \\
Control & $22(12)$ & $75.4(4)$ & $8(2.7)$ & $29.3(0.7)$ \\
\hline
\end{tabular}


Table 2. Summary of behavioural results

\begin{tabular}{llll}
\multicolumn{1}{c}{ Tasks } & max. & $\begin{array}{l}\text { AD } \\
\text { mean(SD) }\end{array}$ & $\begin{array}{l}\text { Control } \\
\text { mean(SD) }\end{array}$ \\
\hline Oral Naming & 50 & $35.9(12.4)$ & $47.8(2.7)^{*}$ \\
Written Naming & 15 & $8.5(3.9)$ & $12.5(1.7)^{*}$ \\
Words dictation & 60 & $43.1(12.5)$ & $53.8(4.6)^{*}$ \\
$\quad$ regular & 20 & $17(3.79)$ & $18.9(1.3)$ \\
$\quad$ rule-based & 20 & $14.1(4.8)$ & $18.3(1.4)^{*}$ \\
$\quad$ arbitrary & 20 & $12(4.8)$ & $16.6(3)^{*}$ \\
Pseudowords dictation & 20 & $16.5(4.1)$ & $19(0.9)$ \\
Text dictation & 23 & $19(5.2)$ & $21.5(1.3)$ \\
Narrative Text & & & \\
$\quad$ T Units & - & $2(1.5)$ & $3.8(1.8)^{*}$ \\
T/T ratio & - & $0.8(0.2)$ & $0.8(0.1)$ \\
\hline * $\mathrm{p}<.005$ in the comparison between $\mathrm{AD}$ and control
\end{tabular}


Table 3. Results of the correlation analyses

\begin{tabular}{|c|c|c|c|c|c|}
\hline \multirow{2}{*}{$\begin{array}{l}\text { Voxels } \\
\text { in cluster }\end{array}$} & \multirow{2}{*}{$\begin{array}{c}\mathrm{Z} \text { value at } \\
\text { local } \\
\text { maximum }\end{array}$} & \multicolumn{3}{|c|}{ Talairach Coordinates } & \multirow{2}{*}{$\begin{array}{c}\text { Brain region } \\
\text { (Brodmann's area) }\end{array}$} \\
\hline & & $\mathrm{x}$ & $\mathrm{y}$ & $\mathrm{z}$ & \\
\hline \multicolumn{6}{|l|}{ Written Naming } \\
\hline 291 & 4.38 & 19 & 62 & 15 & Right Superior Frontal (10) \\
\hline 184 & 4.13 & -45 & -58 & 8 & Left Middle Temporal (39) \\
\hline 234 & 3.68 & -23 & 4 & 7 & Left Putamen \\
\hline 34 & 3.57 & -11 & -95 & -18 & Left Lingual (17) \\
\hline 22 & 3.52 & -22 & -87 & -12 & Left Fusiform (18) \\
\hline 51 & 3.36 & 19 & -67 & 46 & Right Precuneus (7) \\
\hline 15 & 3.35 & -36 & -74 & -2 & Left Inferior Occipital (19) \\
\hline 40 & 3.27 & -24 & -86 & 12 & Left Middle Occipital (19) \\
\hline 21 & 3.24 & -48 & -18 & 34 & Left Postcentral (3) \\
\hline 5 & 3.19 & -45 & -67 & 19 & Left Middle Temporal (39) \\
\hline \multicolumn{6}{|c|}{ Words to Dictation } \\
\hline 69 & 3.34 & 16 & 59 & 17 & Right Superior Frontal (10) \\
\hline \multicolumn{6}{|c|}{ Narrative Text (T Units) } \\
\hline 403 & 4.68 & -45 & -56 & 9 & Left Middle Temporal (39) \\
\hline 274 & 3.97 & -20 & -4 & 4 & Left Globus Palidus \\
\hline 77 & 3.37 & -47 & 21 & -19 & Left Superior Temporal (38) \\
\hline 5 & 3.12 & -42 & 8 & -28 & Left Superior Temporal (38) \\
\hline
\end{tabular}




\section{AD patients}
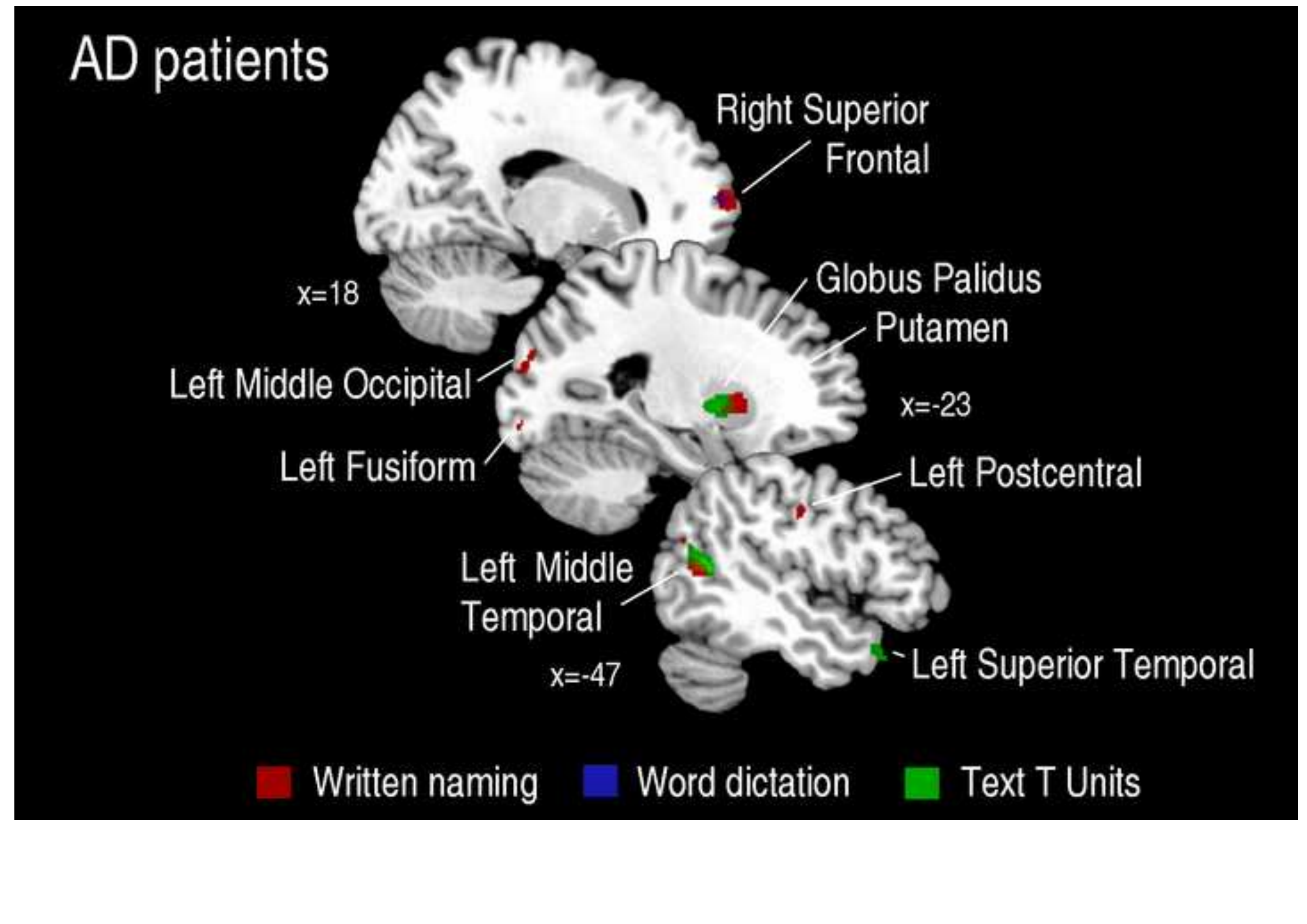